\title{
ARTE "ESQUEMÁTICA" DE AR LIVRE NA BACIA DO AVE (PORTUGAL, NO IBÉRICO): ESPACIALIDADE, CONTEXTO, ICONOGRAFIA E CRONOLOGIA
}

\author{
DANIELA CARDOSO ${ }^{(1)} \&$ ANA M. S. BETTENCOURT ${ }^{(2)}$
}

Resumo:

\begin{abstract}
A primeira compilação de arte rupestre de ar livre realizada para a bacia do Ave, no NO de Portugal, permitiu inventariar um certo número de gravuras que se inserem genericamente na denominada arte de tradição esquemática.

O trabalho realizado, a diferentes escalas de análise, possibilitou dar especial atenção à localização espacial e ao contexto físico de implantação deste tipo de manifestações rupestres; a estudos sobre a morfologia dos afloramentos gravados; à sua iconografia e a eventuais fases de gravação.

Foi colocada a hipótese da existência de duas fases distintas dentro deste tipo de gravuras. Uma primeira, com motivos abstratos, foi considerada Neolítica e a segunda, com antropomorfos com toucados e portadores de mãos grandes, do Calcolítico, perdurando pela Idade do Bronze. Verificou-se, ainda, a frequência destes lugares na longa diacronia através de adições de podomorfos e paletas, genericamente considerados do $1^{\circ}$ milénio a.C

Os responsáveis pela arte esquemática foram consideradas grupos portadores de uma cosmogonia animista.

Palavras-Chave: NO de Portugal, Arte de tradição esquemática, Pré-história Recente, Neolítico-Calcolítico, Animismo.
\end{abstract}

Abstract:

Open air "schematic" art in the Ave basin (Portugal, NW Iberia): spatiality, context, iconography and chronology

The first corpus of rock art corpus created for the basin of the river Ave (NW Portugal) has allowed to identify some "Schematic" rock art places that were synthesize and discuss in this paper.

The data were studied through different perspectives: spatial and physical contexts; morphology of the engraved outcrops and its iconography.

Results allowed to put the hypothesis of two distinct chronological phases. The first one, with abstract motives, was considered to date from the Neolithic. The second phase, characterized by different types of anthropomorphic (with headdresses and large hands), was inserted from the Chalcolithic, enduring throughout the Bronze Age. Many of these places have been active in the long term. This has been materialized by adding or overlapping new motives such as footprints and palettes, which usually date back to the first millennium B.C.

Those responsible for the schematic art were considered to have an animist cosmogony.

Keywords: NW of Portugal, "Schematic" Art, Later Prehistory, Neolithic-Chalcolithic, Animism.

Received: 1 November 2015; Accepted: 10 December 2015

\section{INTRODUÇÃO}

No âmbito do projeto de doutoramento intitulado "A Arte Atlântica do Monte de S. Romão (Guimarães) no Contexto da Arte Rupestre Pós-paleolítica da Bacia do Ave - Noroeste Português", realizado no âmbito de um projeto mais vasto designado "Espaços naturais, arquitecturas, arte rupestre e deposições na préhistória recente da fachada ocidental do centronorte português: das ações aos significadosEnardas" $"$ a autora realizou a primeira sistematização das gravuras rupestres de ar livre, na bacia do rio Ave, cuja temática as inserem na arte de tradição esquemática. A bacia do Ave corresponde a uma área que ocupa cerca de 1400 $\mathrm{km}^{2}$ localizada a norte do Porto e a sul de Braga, duas importantes capitais de distrito existentes no NO de Portugal.

Apesar da predominância de gravuras rupestres inseríveis na gramática decorativa da tradição atlântica (CARDOSO 2015), foi possível identificar nove afloramentos gravados com motivos de tradição esquemática.

\footnotetext{
${ }^{(1)}$ Sociedade Martins Sarmento, Guimarães, Portugal; Laboratório de Paisagem, Património e Território, Lab2PT da Universidade do Minho. E-mail: danyrest@gmail.com

${ }^{(2)}$ Departamento de Historia da Universidade do Minho, Braga - Portugal; Laboratório de Paisagem, Património e Território, Lab2PT da Universidade do Minho. E-mail: anabett@uaum.uminho.pt

${ }^{1}$ O projeto ENARDAS foi aprovado e financiado pela FCT com a referência PTDC/HIS-ARQ/112983/2009. Foi liderado por Ana M. S. Bettencourt, Professora do Departamento de História da Universidade do Minho, desde 1 maio de 2011 até 31 de outubro de 2014. Teve como objetivos estudar o simbolismo dos espaços naturais do Neolítico à Idade do Bronze da fachada ocidental do Centro e Norte português. Esta temática implicou estudos relacionais entre o espaço e as materialidades nele inscritas ou incorporadas, quer em termos sincrónicos, quer diacrónicos, através de uma perspetiva arqueológica que privilegia os atores e os significados inerentes às ações (http://enardas.pt).
} 
Os dados provenientes desta primeira inventariação (ainda que preliminar) veio possibilitar um primeiro estudo sobre este tipo de manifestações artísticas, a diferentes escalas de análise, com o objetivo de conhecer a sua localização espacial, o contexto físico de implantação dos afloramentos gravados, a sua morfologia e iconografia e possíveis fases ou ciclos de gravação, assim como algumas interpretações sobre as cosmogonias das populações que as gravaram.

\section{METODOLOGIA}

Em termos metodológicos baseámo-nos numa postura interpretativa que tem como base as premissas de que todo o conhecimento é subjetivo e de que as ações são tanto reflexo do pensamento simbólico das comunidades, como agentes no seu quotidiano, numa perspetiva próxima de Gell (1998) e de Ingold (2000).

Para a concretização deste trabalho aplicámos duas escalas de análise: a média e a micro. Num primeiro momento e no âmbito de uma escala de análise mais abrangente utilizámos, embora de forma tímida, um Sistema de Informação Geográfica, de forma a analisarmos a implantação dos sítios rupestres no contexto do espaço de estudo. Recorrendo a uma micro escala de análise, analisámos os afloramentos gravados não apenas ao nível do seu contexto físico mas tendo em conta a sua morfologia, iconografia. Foi dada especial atenção à interrelação entre a morfologia dos afloramentos gravados, distribuição da iconografia e audiência, na perspetiva defendida por Bradley (2009), o que permitiu abordagens interpretativas de ordem social e cultural. Concordamos plenamente com este autor quando afirma que as manifestações rupestres podem comportar significados diferentes dependendo de quem as vê "... in time some people may be initiated into the full significance of the imagery, some may never acquire more than a superficial understanding, while others may not be permitted to view it in any circumstances. Some of those distinctions are based on age and gender. In the same way, supposedly figurative images may also be understood metaphorically" (BRADLEY 2009: 45).

Valorizámos, igualmente, o papel da Antropologia partindo do princípio de que a tradição oral constitui uma importante base de informação já que fornece dados sobre os lugares gravados através das lendas e histórias a eles associadas. Tal como outros autores que aplicaram esta metodologia no território português (ALVES 2001, 2008; SANCHES 2003), cremos que este tipo de informação revela um simbolismo ancestral conferido ao lugar pelas comunidades que frequentaram estes espaços ao longo de milénios.

\section{A BACIA DO AVE - CARACTERIZAÇÃo FÍSICA E AMBIENTAL}

A área geográfica da bacia hidrográfica do rio Ave situa-se no Noroeste de Portugal, na região do Baixo Minho (Fig. 1). Encontra-se rodeada pela costa Atlântica, a oeste; pela bacia do Cávado e o

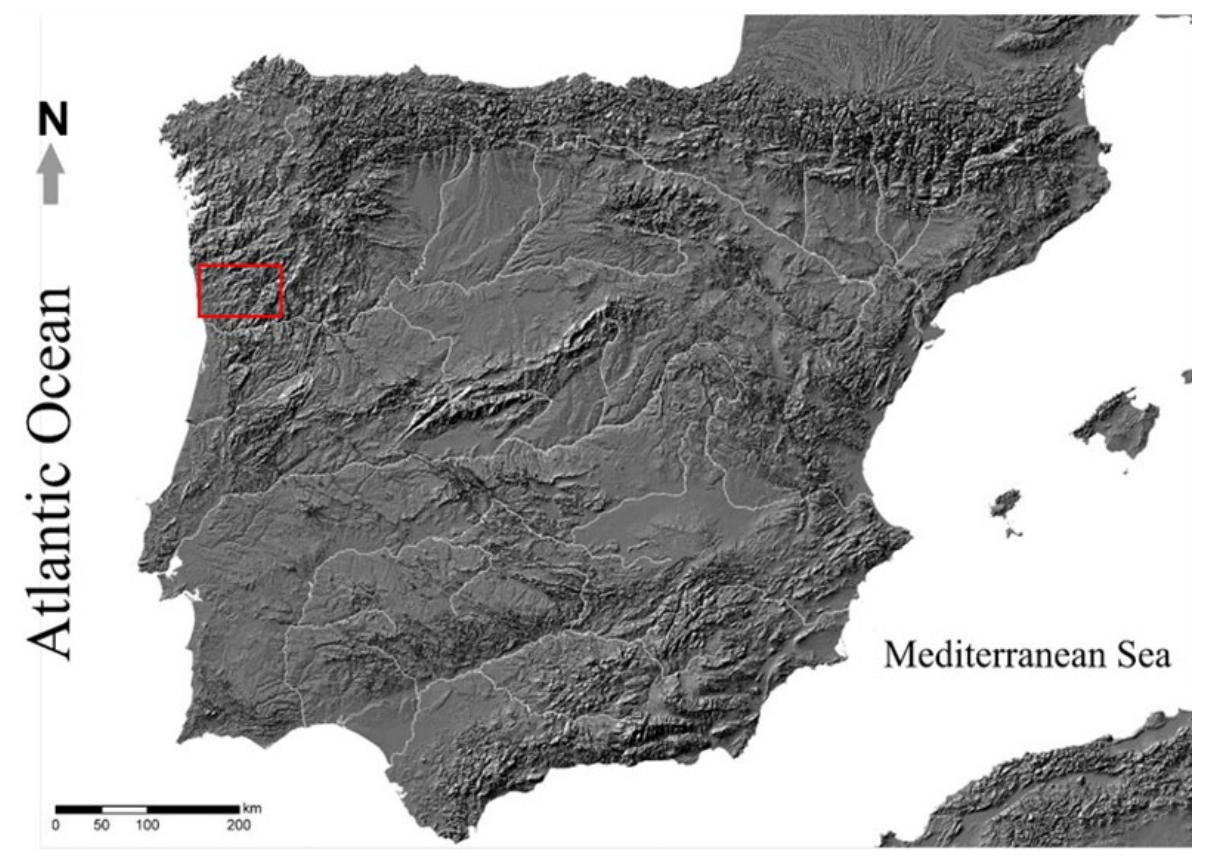

Fig. 1. Mapa da Península Ibérica com a marcação dos limites da bacia do rio Ave.

Fig. 1. Map of the Iberian Peninsula with the boundaries of the Ave river basin. 
Parque Nacional da Peneda-Gerês, a norte; pela região Transmontana, a este e pelas bacias do Leça e Douro, a sul. O rio Ave, que percorre cerca de $100 \mathrm{~km}$, tem as suas cabeceiras a mais de $1050 \mathrm{~m}$ de altitude, na Serra da Cabreira, e vai desaguar em Vila do Conde, no Oceano Atlântico. Da observação do perfil longitudinal deste rio verificase que os maiores declives se encontram nos primeiros $7 \mathrm{~km}$, na área mais montanhosa (COSTA 2007). Os seus principais afluentes encontram-se na margem direita, sendo de destacar o rio Este que exibe um perfil mais regular e cuja bacia apresenta um relevo mais suave sem percurso típico de montanha. Já os afluentes da margem esquerda, os rios Selho e Vizela, apresentam-se com mais irregulares e relevos acentuados. Do ponto de vista geológico, estão presentes os granitos, os quartzitos, os xistos e diversas rochas afins, podendo ainda encontrar-se formações de cobertura do Holocénico (aluviões) e do PlioPlistocénico (terraços fluviais) (COSTA 2007).

\section{OS LUGARES COM ARTE DE TRADIÇÃO ESQUEMÁTICA AO AR LIVRE DA BACIA DO AVE: CARACTERÍSTICAS ESPACIAIS E ICONOGRAFIA}

São 9 os locais inventariados com gravuras de tradição esquemática, todos eles nos municípios de Fafe e de Vieira do Minho, os mais orientais da bacia fluvial (Tabela 1). Todos estes locais eram conhecidos da bibliografia arqueológica ou de websites de promoção do património, embora só 3 deles tivessem sido alvo de decalque. Encontramse neste caso os de Cabanas (SAMPAIO \& GARCIA DIEZ 2000) (Fig. 13); Laje dos Cantinhos/Zebral (Fig. 3) (FONTES \& RORIZ 2007; BETTENCOURT 2014a; CARDOSO 2015) e Pedra Escrita (FONTES \& RORIZ 2007). Estes três últimos lugares foram alvo de descrição mais ou menos detalhada, tendo os restantes sido publicados com descrições sumárias. Como tal foi importante a observação pessoal dos mesmos o que possibilitou, na maioria os casos, obter novos dados (CARDOSO 2015).

Tabela 1. Afloramentos gravados com arte "esquemática" na bacia do Ave.

Table 1. Recorded outcrops with "Schematic" Art in the Ave basin

\begin{tabular}{|c|c|c|c|c|c|}
\hline $\mathbf{N}^{0}$ & $\begin{array}{l}\text { Designação } \\
\text { do sítio }\end{array}$ & Concelho & Freguesia & Iconografia & Referências bibliográficas \\
\hline 1 & Agra 2 & $\begin{array}{l}\text { Vieira do } \\
\text { Minho }\end{array}$ & Rossas & Quadrados segmentados e covinhas. & $\begin{array}{l}\text { http://patrimonio.cm-vminho.pt/; } \\
\text { CARDOSO } 2015 .\end{array}$ \\
\hline 2 & Agra 3 & $\begin{array}{l}\text { Vieira do } \\
\text { Minho }\end{array}$ & Rossas & Quadrados segmentados e covinhas. & $\begin{array}{l}\text { http://patrimonio.cm-vminho.pt/; } \\
\text { CARDOSO } 2015 .\end{array}$ \\
\hline 3 & Cabanas & Fafe & S. Gens & $\begin{array}{l}\text { Covinhas, círculos simples, círculos } \\
\text { associados a sulcos, círculos com } \\
\text { covinha central, posteriormente associa- } \\
\text { dos a cruzes e paletas. }\end{array}$ & $\begin{array}{l}\text { SAMPAIO \& GaRCIA Diez 2000; ABREU } \\
\text { 2012; CARDOSO } 2015 .\end{array}$ \\
\hline 4 & $\begin{array}{l}\text { Chão do } \\
\text { Gandas }\end{array}$ & $\begin{array}{l}\text { Vieira do } \\
\text { Minho }\end{array}$ & Pinheiro & $\begin{array}{l}\text { Covinhas e antropomorfos (?) muito } \\
\text { apagados. }\end{array}$ & $\begin{array}{l}\text { CAMPOS 1998; FONTES \& RORIZ 2007; } \\
\text { ABREU 2012; CARDOSO } 2015 . \\
\text { http://www.geira.pt; } \\
\text { http://patrimonio.cm-vminho.pt/ }\end{array}$ \\
\hline 5 & Bragadas & $\begin{array}{l}\text { Vieira do } \\
\text { Minho }\end{array}$ & Rossas & $\begin{array}{l}\text { Quadrados segmentados, paletas, } \\
\text { cruciformes e } \\
\text { indeterminados }\end{array}$ & $\begin{array}{l}\text { http://patrimonio.cm-vminho.pt/; CARDOSO } \\
2015 \text {. }\end{array}$ \\
\hline 6 & Parada & $\begin{array}{l}\text { Vieira do } \\
\text { Minho }\end{array}$ & Rossas & $\begin{array}{l}\text { Quadrados segmentados, motivos } \\
\text { circulares com estrela e cruzes simples }\end{array}$ & $\begin{array}{l}\text { SARMENTO 1999: 462; CARDOSO } 2015 . \\
\mathrm{http}: / / \text { patrimonio.cm-vminho.pt/; }\end{array}$ \\
\hline 7 & $\begin{array}{l}\text { Laje dos } \\
\text { Cantinhos }\end{array}$ & $\begin{array}{l}\text { Vieira do } \\
\text { Minho }\end{array}$ & Ruivães & $\begin{array}{l}\text { Quadrados segmentados, alguns deles } \\
\text { com covinha em cada segmento; covi- } \\
\text { nhas, antropomorfos esquemáticos, } \\
\text { cruciformes e pentagrama. }\end{array}$ & $\begin{array}{l}\text { http://www.geira.pt; FONTES \& RORIZ } \\
\text { 2007; BETTENCOURT 2014a; CARDOSO } \\
\text { 2015; http://patrimonio.cm-vminho.pt/ }\end{array}$ \\
\hline 8 & $\begin{array}{l}\text { Penedo da } \\
\text { Pegadinha }\end{array}$ & $\begin{array}{l}\text { Vieira do } \\
\text { Minho }\end{array}$ & Pinheiro & $\begin{array}{l}\text { Quadrados segmentados, covinhas, } \\
\text { sulcos, podomorfos. }\end{array}$ & $\begin{array}{l}\text { FONTES \& RORIZ 2007 ; BETTENCOURT } \\
\text { 2014b; www.geira.pt; CARDOSO 2015; } \\
\text { http://patrimonio.cm-vminho.pt }\end{array}$ \\
\hline 9 & $\begin{array}{l}\text { Pedra } \\
\text { Escrita }\end{array}$ & $\begin{array}{l}\text { Vieira do } \\
\text { Minho }\end{array}$ & Cantelães & $\begin{array}{l}\text { Quadrado segmentado, variados tipos } \\
\text { de cruzes e círculo segmentado gravado } \\
\text { com objeto metálico. }\end{array}$ & $\begin{array}{l}\text { SARMENTO 1999: 459; FONTES \& RORIZ } \\
\text { 2007; CARDOSO 2015; } \\
\text { http://patrimonio.cm-vminho.pt/ }\end{array}$ \\
\hline
\end{tabular}

No que se refere à distribuição espacial, na macro escala de análise, verifica-se que a arte de tradição esquemática se concentra, tendencialmente, numa zona mais interior, próxima da nascente do rio Ave, nomeadamente na Serra da Cabreira, com uma altitude de $1262 \mathrm{~m}$ (Fig. 2B) e nas serras de Fafe com $851 \mathrm{~m}$ e de Maroiço com $834 \mathrm{~m}$ de altitudes máximas. Esta distribuição geográfica vai de encontro às considerações de Baptista (1993) e de Alves (2003) que defendem que este tipo de arte tem uma disposição mais continental, desenvolvendo-se de uma forma geral nas regiões mais interiores do Minho, de Trás-os-Montes e da Beira Alta. A esta tendência, contudo, têm sido acrescidos novos dados, como é o caso dos trabalhos realizados no Monte do Góis, em Caminha, no litoral NO onde se salienta o facto de a arte de tradição esquemática poder atingir zonas costeiras (VALDEZ 2010; Alves 2013). Contudo, a base empírica apresentada por estas investigadoras para compro- 
var a existência de arte esquemática no litoral é, ainda, pouco explícita ou sumária, parecendo alguns motivos corresponder a signos de tradição histórica, como cruzes simples ou complexas, com peanhas retangulares ou circulares. No entanto a questão da circunscrição da arte de tradição esquemática poderá, ainda, reservar-nos surpresas futuras, pelo facto de existirem muitas lacunas no âmbito da sua investigação nas áreas mais ocidentais.

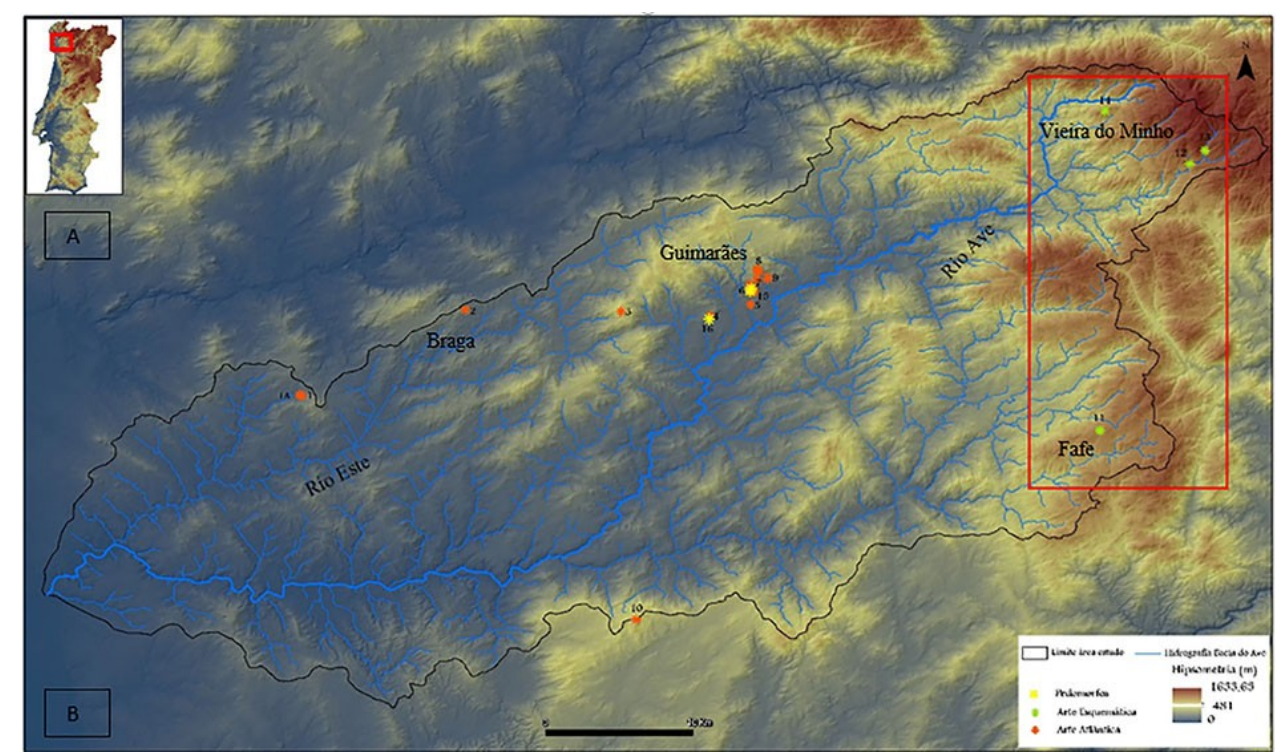

Fig. 2. A - Localização da bacia do Ave em Portugal; B - Mapa hipsométrico assinalando a área de distribuição da arte de tradição esquemática na bacia do Ave e alguns lugares gravados. 11: Cabanas; 12: Parada; 13: Bragadas; 14: Penedo da Pegadinha (CARDOSO 2015 adaptado).

Fig. 2. A - Ave basin location in Portugal; B - Hypsometric map pointing out the area of distribution of "schematic" art and some recorded outcrops, in the Ave basin. 11: Cabanas; 12: Parada; 13: Bragadas; 14: Penedo da Pegadinha (CARDOSO 2015 adapted).

Quanto à implantação dos afloramentos gravados, estes enquadram-se, genericamente, em vertentes montanhosas, que se disseminam por altitudes que variam entre os 600 e os $1000 \mathrm{~m}$, em locais que se relacionam, espacialmente e visualmente com a água, materializada por nascentes, lameiros, ribeiros e rios. Esta relação é bem percetível no afloramento gravado de $\mathrm{Ca}$ banas (Fafe) onde, nas proximidades, os rios Ferro e Bugio correm em direção ao rio Vizela, um dos afluentes do Ave. Também no concelho de Vieira do Minho, onde se concentra a maioria dos casos de estudo, estes encontram-se vinculados com a nascente do rio Ave - uma zona intimamente irrigada e com grande número de linhas de água. Por exemplo, na envolvência das gravuras rupestres da Laje dos Cantinhos/Zebral circulam as águas das ribeiras da Peneda e dos Gaviões; nas proximidades da Pedra Escrita e do Penedo da Pegadinha corre a ribeira de Cantelães e nas proximidades de Bragadas e Parada corre o rio Ave (CARDOSO 2015).

Em termos da sua acessibilidade todas estas gravuras ficam em lugares de passagem e de acesso pedestre, relativamente fácil, a partir do vale.

Os afloramentos gravados são em granito biotítico, um mineral que se caracteriza por apre- sentar uma cor escura, de grão médio a fino, com exceção de Cabanas em que o granito tem um grão médio a grosseiro, de duas micas.

As áreas dos afloramentos escolhidas para serem gravadas foram, maioritariamente, as superfícies superiores aplanadas, dispostas na horizontal ou ligeiramente inclinadas, em afloramentos algo destacados do solo. A Pedra Escrita é excecional por ter sido gravada numa face vertical.

Relativamente ao número de motivos por afloramento verifica-se que a maioria $(62,5 \%)$ contém entre 4 a 7 motivos gravados. Os restantes encontram-se profusamente gravados. Por exemplo, a Pedra Escrita tem cerca de 60 motivos; Cabanas tem cerca de 95 e a Laje dos Cantinhos, mais de 140 (Fig. 3). De notar, no entanto, que nestes três afloramentos observam-se adições posteriores ao primeiro momento de gravação. Mas estas também ocorrem noutros afloramentos com menor número de motivos, assunto que voltaremos a discutir.

No que diz respeito à audiência, o facto dos afloramentos gravados terem, na sua generalidade, consideráveis dimensões, serem pouco elevados e se encontrarem tendencionalmente na horizontal, faz-nos supor que o espaço circundante ofereceria condições para uma vasta audiência disposta em situação de igualdade física. 


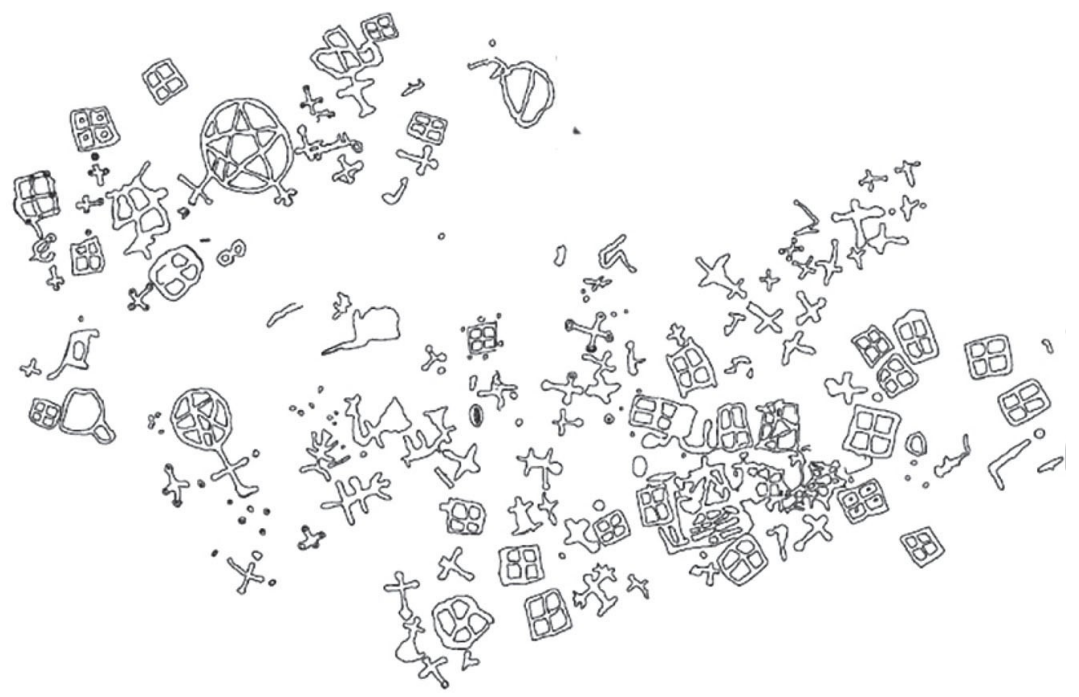

Fig. 3 Laje dos Cantinhos/Zebral (FonTES \& RoRIZ 2007 adaptado).

Fig. 3. Laje dos Cantinhos/Zebral (FonTES \& RORIZ 2007 adapted).

No que se relaciona com o reportório iconográfico mais antigo é de referir que a diversidade é reduzida e que se baseia na existência de motivos geométricos, como quadrados e retângulos, internamente segmentados, por vezes de cantos arredondados, e covinhas. Com menor representação existem círculos simples ou com covinha central, sulcos, e, finalmente, antropomorfos de diferentes tipos (Fig. 4)

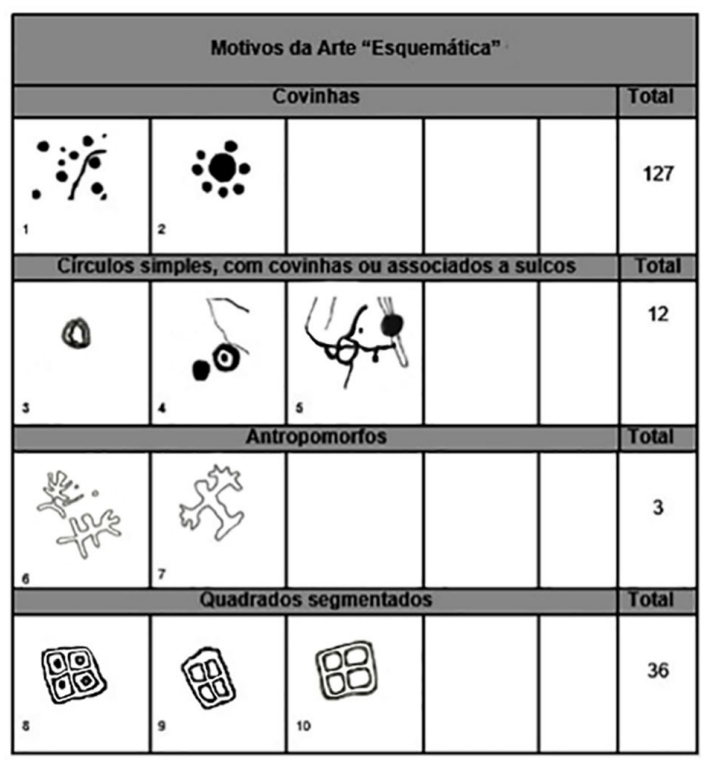

Fig. 4. Motivos da arte "esquemática" na bacia do Ave. 1 2: Cabanas; 3: Laje dos Cantinhos; 4: Cabanas; 5, 6, 7 e 8: Laje dos Cantinhos.

Fig. 4. "Schematic" art motifs in the Ave basin. 1 and 2: Cabanas; 3: Laje dos Cantinhos; 4: Cabanas; 5, 6, 7 and 8: Laje dos Cantinhos.
Os mais representados são, além das covinhas e dos conjuntos de covinhas (71\%), os quadrados ou retângulos segmentados $(20 \%)$, sendo mais raros os círculos (7\%) e os antropomorfos (2\%).

Quanto aos motivos posteriormente adicionados à arte de tradição esquemática são de referir as paletas; os podomorfos; os vários tipos de cruciformes (como cruzes latinas simples ou de base circular e cruzes gregas) e os pentagramas (Fig. 5).

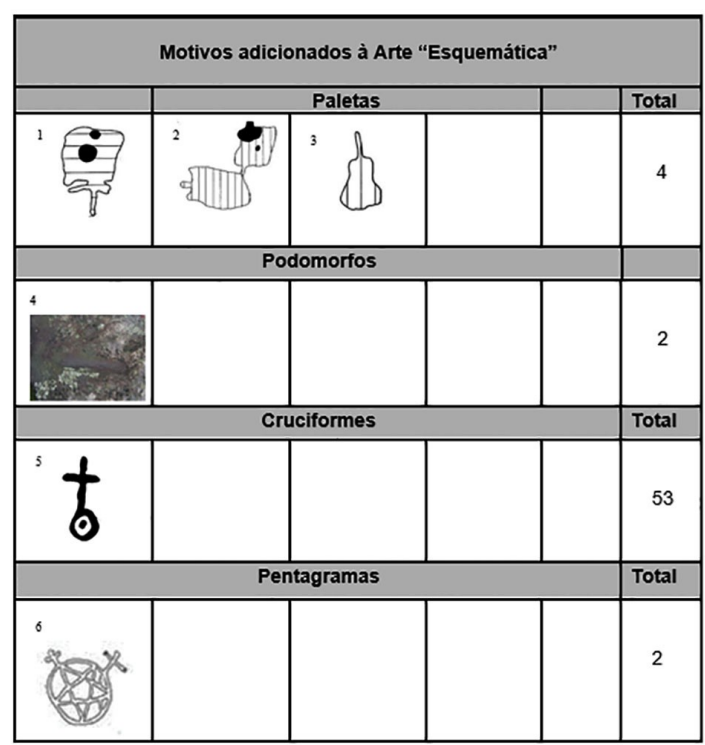

Fig. 5. Motivos adicionados à arte de tradição esquemática na bacia do Ave. 1, 2 e 3: Cabanas; 4: Penedo da Pegadinha; 5:Cabanas; 6: Laje dos Cantinhos.

Fig. 5. Added motifs to the schematic tradition art in the Ave basin. 1, 2 and 3: Cabanas; 4: Penedo da Pegadinha; 5:Cabanas; 6: Laje dos Cantinhos. 
Estes motivos correspondem, nos contextos em estudo, à última fase de gravação, não sendo típicos deste tipo de arte (CARDOSO 2015). Aliás já Bettencourt et al. (in press), defenderam que estes motivos correspondem a uma tradição iconográfica distinta quer da arte de tradição esquemática quer atlântica, pois tanto aparecem isolados, como associados a diferentes tradições artísticas, nestes casos, como adições ou sobreposições.

\section{DISCUSSÃO DOS DADOS E INTERPRETAÇÕES}

\section{1. Espacialidade, contexto e cosmogonia}

Apesar dos casos de estudo serem ainda escassos, consideramos útil sintetizar as nossas considerações como base para discussão em futuros trabalhos.

Apesar de à média escala de análise, no caso concreto a bacia do Ave, existir uma diversidade espacial entre a arte de tradição esquemática e a de tradição atlântica, como se se excluíssem, à micro escala admitimos que há vários pontos comuns entre estas duas tradições pois ambas se encontram em locais de passagem, se relacionam com cenários aquáticos e se localizam nos mesmos tipos de afloramentos quer em termos petrográficos quer topográficos.

$\mathrm{O}$ fato de sítios com arte rupestre de tradição esquemática serem facilmente acessíveis e se localizarem em áreas relacionadas com bacias de receção, também foi notado para núcleos rupestres existentes a sudoeste do Monte de Góis, em Lanhelas, Caminha, nomeadamente a Mata das Cruzes e o vale do Rio do Ouro, ambos localizados num anfiteatro natural (ALVES 2008, 2013). O mesmo se pode considerar para o Gião I e II, nos Arcos de Valdevez (ALVES 2008).

Quase todos os loci em estudo teriam a possibilidade de terem uma vasta audiência pelo que poderiam ter funcionado, facilmente, como locais de encontro, de reunião e de cerimónias para um grupo vasto de pessoas.

Se é possível admitir que a gravação destes lugares materializa ou potencia os seus significados originais, então é de admitir que determinados afloramentos, cursos de água e lugares de passagem teriam propriedades para as populações pré-históricas, numa lógica do pensamento animista.

Dada a importância destes lugares gravados cremos, ainda, que muitos deles permaneceram ativos na longa duração, quer através da memória oral quer através das adições de motivos, sendo, portanto, lugares multisignificantes na longa duração e passíveis de vivências e de experiências distintas. Pela análise da iconografia, das técnicas, das localizações dos motivos no afloramento e da toponímia, coloca-se a hipótese de que estes lugares tiveram uma longa biografia mantendo-se ativos na memória das populações, certamente com adições e alterações de significados em relação aos originais. Aliás, a maior expressão de adição nota-se em momentos em que se pretendeu alterar o sentido real ou imaginado destes lugares, inserindo-os na lógica do cristianismo. A materialização desta ideia parece estar patente no Penedo da
Pegadinha, com uma lenda associada ao cristianismo (FONTES \& RORIZ 2012; CARDOSO 2015); nas Bragadas, onde foram gravadas cruzes com covinhas nas extremidades; em Cabanas, onde diversas cruzes com peanhas, neste caso circulares, por vezes parecendo aproveitar círculos pré-existentes, indiciam uma fase de gravação da Idade Média, segundo Sampaio \& Garcia Diez (2000). Algumas poderão indiciar, de um modo geral, repetidas demarcações de limites territoriais (FONTES \& RORIZ 2007).

De notar que a memória destes lugares como sendo significantes permaneceu quando em Agra 2 se gravou a imagem do que parece um coelho e na Laje dos Cantinhos, em Agra 2 e 3, em Parada e em Bragadas quando as populações associaram as gravuras dos quadrados segmentados ao jogo lúdico designado por "jogo dos cantinhos".

A perduração no tempo destes lugares também se pode interpretar naqueles que detêm um topónimo específico, como Cabanas, Laje dos Cantinhos, Penedo da Pegadinha e Pedra Escrita.

Este fenómeno da longa temporalidade dos lugares gravados com arte de tradição esquemática tem vindo a ser observado em muitas outras áreas do Norte de Portugal. Referimos, por exemplo, o caso do Fieiral, em Melgaço (BETTENCOURT \& RODRIGUES 2013), a vertente sudoeste do Monte de Góis (ALVES 2008, 2013), o Gião I e II (ALVES 2008), a Chã da Rapada (BATISTA 1986; MARTINS 2006; Alves 2012; BETTENCOURT 2013b). Para o Centro-Norte, há ainda a referir o exemplo dos complexos rupestres do planalto do Fial, Tondela (SANTOS 2008).

Apesar destas considerações, ficam por explicar muitas outras questões em torno das narrativas inerentes aos diferentes lugares gravados por ser difícil a sua interpretação sem um estudo holístico, e sem a sua interrelação, em rede, com outros lugares, como os povoados, os contextos funerárias, etc., estudos que estão por fazer para a pré-história desta área geográfica.

\subsection{Iconografia e cronologia}

A atribuição cronológica da arte de tradição esquemática de ar livre é extremamente complexa. Desde os inícios do séc. XX que se tem assistido a várias tentativas de enquadramento cronológicocultural das representações que comummente comportam características de tendência esquematizada. Entre as várias perspetivas são de salientar as propostas realizadas para o Noroeste Ibérico por Obermaier (1925) que, com o seu Ältere Grüppe, as insere numa época posterior ao Neolítico; por Gimpera (1923) que as considera como do seu grupo A, inserível no Calcolítico; por Anati (1968) que as integra nas suas $4^{\mathrm{a}}$ e $5^{\mathrm{a}}$ fases, correspondentes ambas à Idade do Ferro e por Martinho Baptista (1983-84) que as coloca no seu grupo II e as baliza entre o Bronze Final e a Alta Idade Média, devido à existência de motivos cruciformes, salientando, no entanto que alguns são antropomórficos. Mais tarde, Sanches $(1997,2002,2006)$ ao estudar os abri- 
gos pintados da Serra de Passos, em Trás-osMontes, considerou-os como sendo Neo-Calcolíticos, com base em analogias e escavações realizadas em alguns deles. Bradley et al. (2005) e Alves et al. (2013), também com base no estudo efetuado no abrigo de El Pedroso, Zamora, consideram que as gravuras esquemáticas aí existentes poderão ser resultado de duas ocupações: uma mais antiga, atribuível ao Neolítico e outra mais recente já do Calcolítico Final /Bronze Inicial.

Recentemente, Sofia Figueiredo (2013: 194195), ao estudar os abrigos pintados do Nordeste Transmontano (distrito de Bragança), considerou, através da aplicação de um método estatístico, a existência de dois grupos: um mais antigo (grupo I) balizado entre o Neolítico Inicial e o Neolítico Final, composto por motivos figurativos e geométricos ou abstratos (representações antropomórficas simples, por vezes associadas a zoomorfos; barras; tectiformes e ramiformes). O segundo grupo (grupo II), entre o Calcolítico e a Idade do Bronze Antigo e Médio, seria caracterizado por motivos antropomórficos mais complexos e pormenorizados contendo, por vezes, elementos etnográficos, como toucados; motivos abstratos e geométricos extremamente complexos e a quase inexistência de motivos zoomórficos.

Já fora do Norte, mas ainda no que se pode considerar Centro-Norte, cabe destacar o trabalho de Santos (2008: 103) que considera a arte esquemática do Fial, em Tondela, Viseu, de entre a segunda metade do $4^{\circ}$ milénio e os inícios do $3^{\circ}$ milénio a.C.

No caso da bacia do Ave, a falta de escavações arqueológicas em redor dos locais gravados e a falta de vinculação direta com outros contextos arqueológicos pré-históricos, possibilitou, apenas, uma proposta de atribuição cronológica hipotética. Esta foi apoiada, essencialmente, em analogias estilísticas com a arte megalítica e com abrigos pintados do Nordeste do território português.

À semelhança de outras áreas geográficas do Noroeste Ibérico consideramos a hipótese de terem existido, na arte de tradição esquemática da bacia do Ave, duas fases de gravação, num processo que se terá iniciado no Neolítico e permanecido pelo Cal-
colítico/Bronze Inicial. Posteriormente, já no âmbito de outros ciclos artísticos (CARDOSO 2015) ter-se-ão verificado adições posteriores, quer durante o $1^{\circ}$ milénio a.C. quer em vários momentos históricos.

Assim, numa primeira fase, inserimos, hipoteticamente, os círculos simples ou com covinha no seu interior e os quadrados segmentados, com ou sem covinhas no interior de cada segmento. De lembrar que em Lamelas, em Ribeira de Pena, os quadrados segmentados parecem associar-se a circulos com covinha interior, conforme pudemos observar pessoalmente.

Estes dois tipos de motivos fazem lembrar alguns existentes na arte megalítica. Como exemplo dos círculos na arte megalítica referimos o caso do dólmen de Dombate, em Cabanas, Corunha (BELlo DiÉGuez 1994); a Mamoa 2 do Alto da Portela de Pau, em Melgaço (BAPTISTA 1997); o dólmen de Madorras 1, em Sabrosa (CRUZ \& GonçALVES 1994); o dólmen 1 de Chã de Parada, em Baião (SHEE 1981) e o dólmen 2 de Chão Redondo, em Sever do Vouga (SANCHES 2008-2009). Quanto aos exemplos de motivos retilíneos podemos referir, de novo, o dólmen de Dombate, em Cabanas, Corunha (BELlo DiÉGUeZ 1994); a Mamoa de Leira das Mamas, em Braga (BeTtencourt 2013a: 73) (Fig. 6A); o dólmen d'Areita, em S. João da Pesqueira onde, sobre uma composição reticulada, há um quadrado segmentado (GOMES et al. 1998) Fig. 6C); os esteios laterais do dólmen de Antelas (SANCHES 2008-2009); o dólmen 1 da Aliviada, Arouca, onde, num dos esteios da câmara, há um quadrado segmentado, associado a sulcos e duas linhas meandriformes (SILVA 1984 in SILVA 2004: 90) (FIG. 6B). É certo que alguns dos motivos retilíneos da arte megalítica podem assumir várias formas, como losangos ou reticulados, diferentes dos quadrados ou retângulos segmentados que se gravam ao ar livre. Alguns deles são pintados, técnica que poderá ter com mais facilidade um traço bem delineado, embora a questão também possa ser cultural, sendo os motivos de ar livre mais "padronizados". No entanto, o que parece relevante é a importância de figurações de traço retilíneo, desde o Neolítico que vão sendo cada vez mais recorrentes.
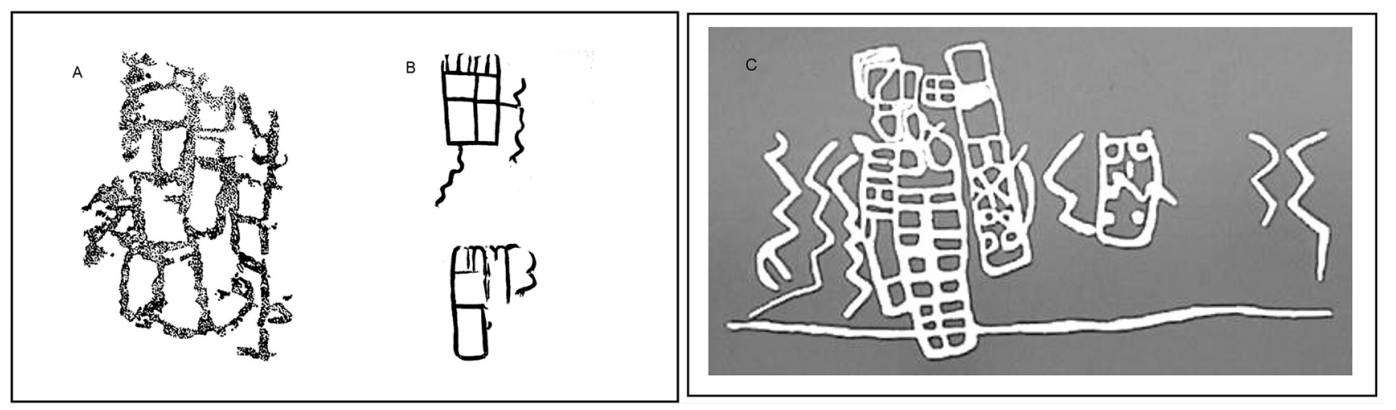

Fig. 6. A - Decalque de um dos esteios pintados da Mamoa da Leira das Mamas, Braga (BetTenCOURT 2013a); B - Motivos gravados no dólmen 1 da Aliviada, Arouca (SILVA 1984 in SILVA 2004: 90, adaptado); C - Motivos do esteio de cabeceira do dólmen de Areita, S. João da Pesqueira. (http://www.360portugal.com/Distritos.QTVR/Viseu.VR/Megalithic/Dolmen_Areita/Introduction.html).

Fig. 6. A - Tracing of one of the painting mainstay of Leira das Mamas mound, Braga (BETTENCOURT 2013a); B -Engraved motives of the passage grave of Aliviada 1, Arouca (SILVA 1984 in Silva 2004: 90, adapted). C - Motives of the bedside mainstay of passage grave of Areita, S. João da Pesqueira; (http://www.360portugal.com/Distritos.QTVR/Viseu.VR/Megalithic/Dolmen_Areita/Introduction.html). 
De notar, ainda, no âmbito da arte de tradição esquemática, a existência de quadrados segmentados associados a círculos raiados (comuns na arte megalítica), no Gião 2, Arcos de Valdevez (BATISTA 1981). Também há que lembrar que, no contexto da arte atlântica, o Forno dos Mouros, em Sever do Vouga, apresenta motivos reticulados sobrepostos por composições circulares indiciando que aqueles são mais antigos (ALVES 2003, 2008).

Quadrados segmentados encontram paralelos gravados em muitos outros lugares do Noroeste Ibérico, desde Campo Lameiro, em Pontevedra, onde os vimos pessoalmente, como no Gião I e II, em Arcos de Valdevez (BAPTISTA 1980) (Fig. 7A), no Outeiro da Botelhinha, em Alijó (LIMA 20082009) (Fig. 7B) e, mais a sul, nos complexos rupestres do Meal da Dona e do Fial, em Tondela, Viseu (SANTOS 2008), embora raros.

Sob a forma de pintura podem encontrar-se nos abrigos do Regato das Bouças 3, na Serra de Passos, em Mirandela (SANCHES 1997, 2002; FigueIREDo 2013) ou no Cachão da Rapa, em Carrazeda de Ansiães (Fig. 7C) (SANTOS JÚNIOR 1934; TEIXEIRA 2012).

No campo das analogias será ainda de referir o já citado abrigo da Casa do Moro/El Pedroso, em
Zamora, onde se encontraram, entre outros motivos, grelhas retangulares e quadrangulares. Segundo os investigadores que ali realizaram trabalho de investigação (BRADLEY et al. 2005; ALVES et al. 2013) identificaram-se neste sítio cronologias distintas a partir de dados provenientes das escavações arqueológicas nas duas câmaras que constituem o abrigo, pelo que deduziram que, tanto o abrigo como os terraços terão usufruído de duas ocupações, uma no Neolítico e outra no Calcolítico Final, Bronze Inicial.

Assim, perante os dados obtidos parece-nos admissível colocar a hipótese de que os quadrados ou retângulos segmentados da arte rupestre de ar livre se possam ter começado a gravar no Neolítico Médio/Final, talvez entre o final do $5^{\circ}$ /inícios do $4^{\circ}$ milénios a.C. embora admitamos que possam ter perdurado. De notar que, embora as datas de radiocarbono obtidas para a pintura megalítica do Noroeste Ibérico sugiram, essencialmente, a sua execução na primeira metade do $4^{\circ}$ milénio a.C., existem datas que recuam este fenómeno até aos finais do $5^{\circ}$ milénio a.C. (CARRERA 2011). Apesar de carecerem de confirmação são datas que não podem ignorar-se.

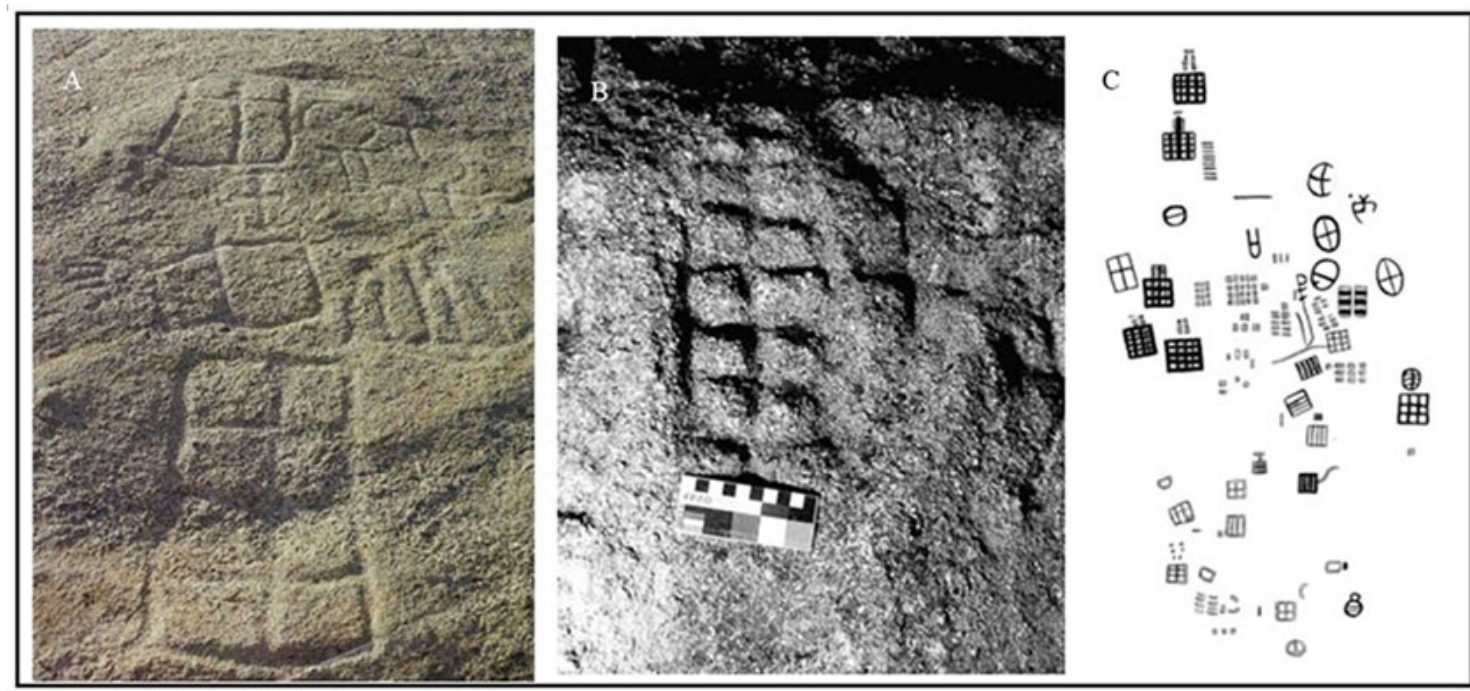

Fig. 7. A - Pormenor de reticulados do Gião I (BAPTISTA 1993); B - Reticulado da Botelhinha (LiMA 2008-2009); C - Painel pintado do Cachão da Rapa seg. Santos Júnior 1930 (ABREU 2012).

Fig. 7. A - Detail of reticulated motives of Gião I (BAPTISTA 1993); B - Botelinha reticulated motives (LIMA 2008-2009); C - Painted panel of Cachão da Rapa after Santos Júnior 1930 (ABREU 2012).

Numa hipotética segunda fase de gravação estaria patente a temática antropomórfica. Dentro deste grupo existem alguns motivos atípicos na arte de ar livre, como os antropomorfos com toucados/ penachos, em posição de movimento, ou com mãos grandes. Estas manifestações foram observadas, até agora, apenas na Laje dos Cantinhos/ Zebral, em Vieira do Minho. Os antropomorfos com toucados/ penachos foram gravados num espaço operativo vazio, entre dois painéis de quadrados segmentados (Figs. 3 e 8A). Também o antropomorfo com mãos grandes parece ter sido encaixado num espaço vazio, entre dois quadrados segmentados, na periferia de um dos painéis compostos por estes motivos. Para o primeiro tipo (com toucado) podem assinalar-se paralelos estilísticos, embora pintados, nos abrigos de Penas Róias, Mogadouro (Figs. 8B e 8C), do Regato das Bouças, na Serra de Passos, Mirandela (SANCHES 1990, 2006) e de Valdejunco, na Serra de Arronches, em Portalegre (BREUIL 1917) (Fig. 8D).

Sob a forma de gravura são de referir os 
exemplos de antropomorfos deste tipo na Rocha dos Namorados, na Guarda (ABREU 2012: 458) (Fig. 8E), em Tripe, Chaves (Fig. 8F) e, já em território espanhol, no abrigo de El Pedroso, em Zamora, bem como outros abrigos na Serra Morena e na Baixa Andaluzia (SANCHES 1997).

$\mathrm{Na}$ década de 80, Baptista refere que a Arte Esquemática ao ar livre parece ter sido influenciada pela expansão pictórica e que alguns motivos antropomórficos, com certos atributos, podiam descender de idênticos modelos pintados (BAPTISTA 1983-84: 76). Para obtenção de cronologias para estes motivos contribuíram os estudos de Sanches nos abrigos pintados da Serra de Passos, como o do Buraco da Pala, Mirandela (SANCHES 1997). Para a autora os motivos antropomórficos "emplumados/com penachos" inserem- se na sua $2^{\mathrm{a}}$ fase, provavelmente entre os finais do $3 \%$ inícios do $2^{\circ}$ milénios a.C. (SANCHES 1997, 2002: 75-76). Já Figueiredo (2013: 223) coloca este tipo de antropomorfos no seu grupo II, desde o Calcolítico até à Idade do Bronze, entre os finais do $4^{\circ}$ milénio a momento incerto do $3^{\circ}$ milénio a.C.

Baseando-nos nestes dados podemos admitir que, tal como para os antropomorfos com penachos/toucados pintados de Trás-os-Montes, os motivos semelhantes da Laje dos Cantinhos/ Zebral, podem integrar-se, entre o $3^{\circ}$ e os inícios do $2^{\circ}$ milénios a.C.

Mais difícil parece ser a atribuição cronológica do antropomorfo com mãos grandes que se assinala na Laje dos Cantinhos visto este motivo ocorrer desde o Neolítico até à Idade do Bronze.

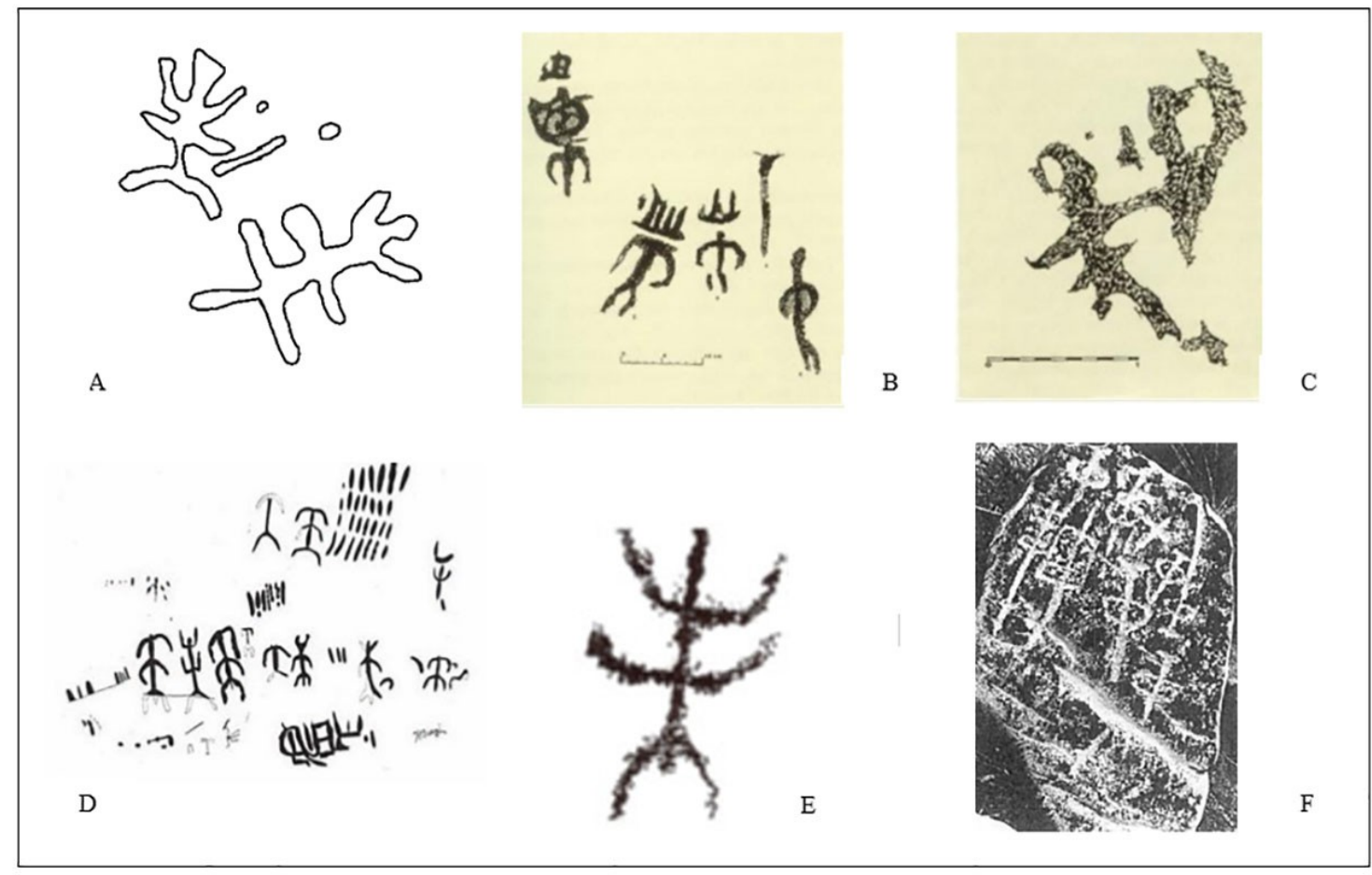

Fig. 8. A - Antropomorfos de toucado da Laje dos Cantinhos/Zebral (adaptado de FonTES \& RORIZ 2007); B - Penas Roias, Mogadouro (AlmeIDA \& Mourinho 1981); C - Penas Roias, Mogadouro (Almeida \& Mourinho 1981); D - Abrigo de Valdejunco, Portalegre (Breuil, 1917 fig. 5); E - Rocha dos Namorados, Guarda (ABREU 2012: 458); F - Antropomorfos de toucado, Tripe, Chaves (BAPTISTA 1983-84).

Fig. 8. A - Headdresses anthropomorphic figures from Laje dos Cantinhos / Zebral (adapted from FonTES \& RoRIZ 2007); B - Penas Roias, Mogadouro (ALMEIDA \& MouRINHO 1981); C - Penas Roias, Mogadouro (ALMEIDA \& MouRINHO 1981); D - Rock shelter of Valdejunco, Portalegre (BREUIL 1917, fig. 5); E - Rocha dos Namorados, Guarda (ABREU 2012: 458); F - Headdresses anthropomorphic figures, Tripe, Chaves (BAPTISTA 1983-84).

Em contextos megalíticos, antropomorfos com mãos grandes ocorrem, apenas no dólmen da Eireira, em Afife, Viana do Castelo (SILVA 1988, 1997) (Fig. 9A).

Também em contextos gravados com arte de tradição esquemática se podem encontrar paralelos. Tal é o caso da Chã da Rapada, em Ponte da Barca (Martins 2006; BetTenCourt 2013b) (Fig. 9B); do Gião I, nos Arcos de Valdevez (BAPTISTA 1993); da rocha 28 de Mairos, Tripe, Chaves (JORGE \& JORGE 1991) (Fig. 9D); da rocha das Ferraduras, na Abelheira, em Seia (RIBEIRO 2008). Sob a forma de pintura esquemática é de referir a existência destes motivos no abrigo das Lapas Cabreiras, em Figueira de Castelo Rodrigo (ABREU 2012). 


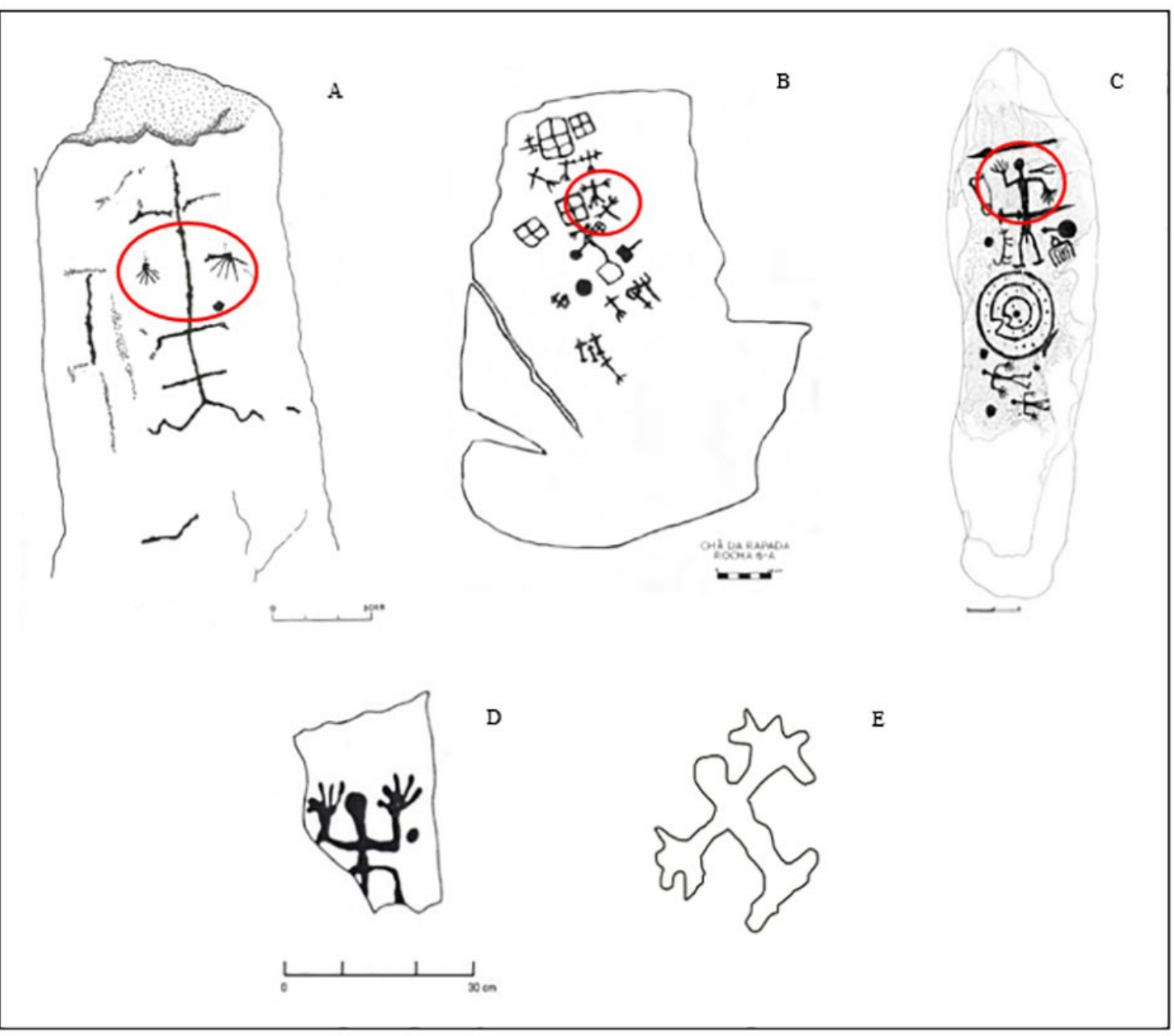

Fig. 9. A - Esteio do dólmen de Eireira (SILva 1997); B - Decalque da rocha 6A da Chã da Rapada (MARTINS 2006); C - Estela de Ervidel II (GOMES 2010); D - Rocha 28 de Mairos (JORGE \& JORGE 1991); E - Antropomorfo da Laje dos Cantinhos (FonTES \& RORIZ 2007 adaptado).

Fig. 9. A - One of the mainstay of Eireira pessage grave (SILVA 1997); B - tracing of the rock 6A of Chã da Rapada (MARTINS 2006); C - The stele of Ervidel II (GOMES 2010); D - Rock 28 of Mairos (JORGE \& JORGE 1991); E - The anthropomorphic figure with big hands of Laje dos Cantinhos (FonTES \& RORIZ 2007 adapted).

De integração estilística mais incerta são as gravuras do Penedo do Matrimónio, em Montalegre que foi inserido no Calcolítico/Bronze Inicial pelos investigadores que realizaram o seu primeiro levantamento (BETTENCOURT et al. 2004) (Fig. 10).

Em contextos mais tardios atesta-se a presença da temática antropomórfica com mãos grandes, entre as estelas da Idade do Bronze Inicial/Médio do sul de Portugal, denominadas também do tipo alentejano ou do tipo I, e das estelas estremenhas da Idade do Bronze Final ou do tipo II (GOMES 2010: 341).

Nas estelas do sul de Portugal é de assinalar a do Ervidel II, encontrada junto a duas cistas de inumação do Bronze Inicial/Pleno, na Herdade de Pomar, Beja (Fig. 9C) e a estela da Figueira, em Vila do Bispo (Gomes 2010; DíAZ-GuARDAMINo 2010). Segundo esta autora, as estelas decoradas, desta área, têm uma cronologia situada entre os 2000/1800-
1400/1200 a.C. (DÍAZ-GUARDAMINO 2010: 386). Nas estelas da fase II é possível observar esta temática nas de Monte Blanco-Olivenza, Magacela, Quintérias-Herrera del Duque, Esparragosa de Lares 1, todas em Badajoz, e na estela de Torrejón Rubio 3, em Cáceres (DÍAZ-GuARDAMINO 2010).

A partir destas observações pode inferir-se que esta temática, sendo muito rara na arte megalítica do Neolítico, deverá enquadrar-se, possivelmente, num momento posterior ao Neolítico e anterior à Idade do Ferro.

A terceira fase de gravação nesta área da arte de tradição esquemática relaciona-se com a reinterpretação destes antigos lugares gravados e corresponderá a um novo ciclo artístico onde se incluem paletas (Fig. 11A), motivo raro que pode ser enquadrado em distintos grupos estilísticos, ou seja, tanto podem aparecer na Arte Atlântica, como na arte de tradição esquemática como isolado (BETTENCOURT et al. in press). Em associação com 
a arte de tradição esquemática do Noroeste português temos conhecimento da sua existência no Outeiro Machado, em Chaves (SANTOS JÚNIOR 1978) (Fig. 11B); em Tripe, Chaves (BAPTISTA
1983-84: 77); no Fieiral 2, em Melgaço (BETTENCOURT \& RodRigues 2013) (Fig. 11C) e na Chã da Rapada, em Ponte da Barca (MARTins 2006: 67) (Fig. 11D).

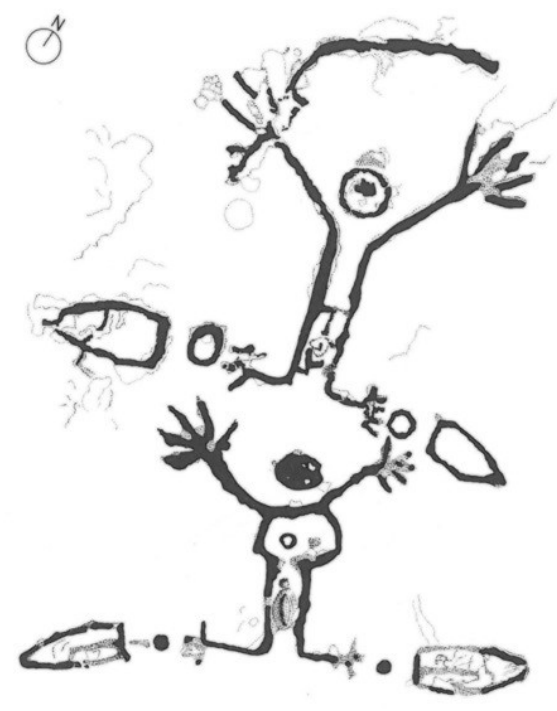

- is
Fig. 10. Decalque do Penedo do Matrimónio (Bettencourt et al. 2004).

Fig. 10. Tracing of Penedo do Matrimónio (Mariage Outcrop) (BETTENCOURT et al. 2004)
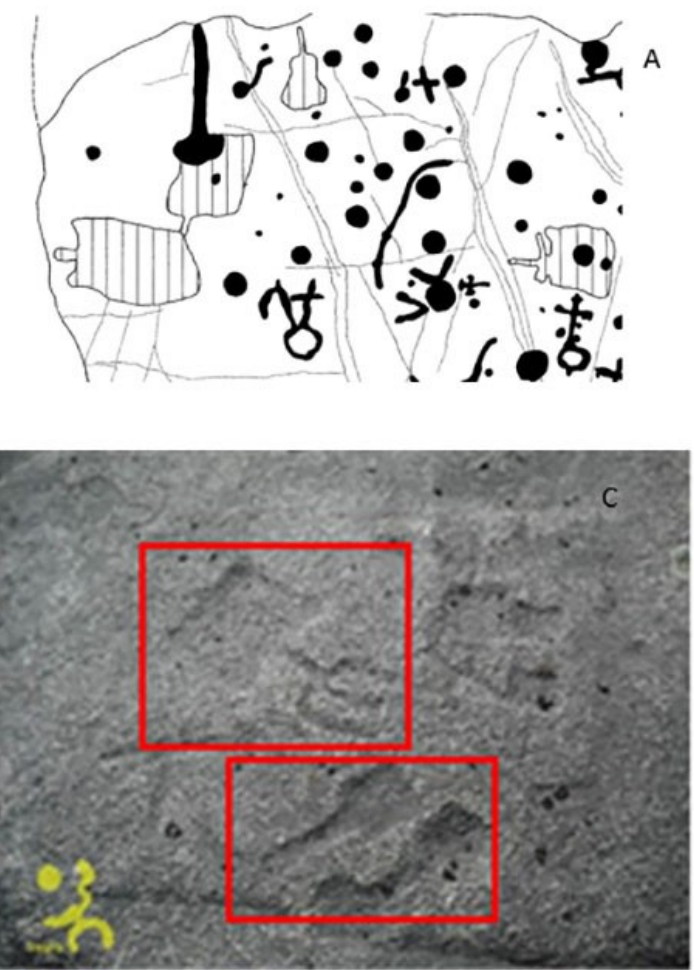

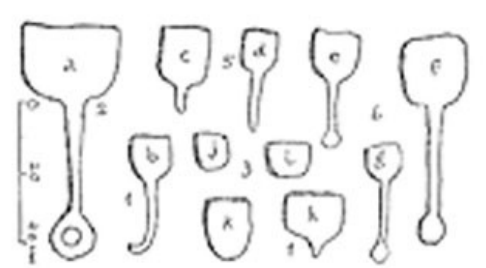

B

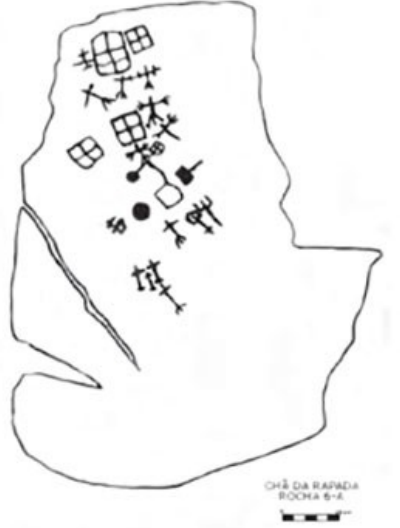

(

Fig. 11. A - Decalque do afloramento gravado de Cabanas (SAMPAIO \& GARCIA DIEZ 2000, adaptado); B - Variedades de paletas do Outeiro Machado (SANTOS 1978: 225); C - Fieiral 2, onde se nota que as paletas alteram os antropomorfos (BETTENCOURT \& RODRIGUES 2013); D - Decalque da rocha 6A da Chã da Rapada (MARTINS 2006).

Fig. 11. A - Tracing of the carved outcrop from Cabanas (SAMPAio \& GARCiA DiEZ 2000, adapted); B - Variety of palettes from Outeiro Machado (SANTOS 1978: 225); C - Fieiral 2, where it is perceivable that the palettes overlay the anthropomorphic motives (BETTENCOURT \& RODRIGUES 2013); D - tracing of the rock 6A of Chã da Rapada (MARTINS 2006). 
$\mathrm{Na}$ sua generalidade estas representações podem ser integradas no grupo II de Baptista, cronologicamente inserível entre a Idade do Bronze e a Alta Idade Média (BAPTISTA 1983-84). Já Martins (2006: 67), a partir do caso de estudo da Chã da Rapada, coloca estes motivos entre a Idade do Bronze e a Idade do Ferro. Segundo Santos Estévez (2005: 50), na Galiza, as paletas, pelas suas semelhantes com as encontradas em contextos funerários em Itália, deverão integrar-se na primeira metade do séc. IX a.C., ou seja, na Idade do Bronze Final, início da Idade do Ferro, embora “... dicha identificación no deja de ser controvertida, habida cuenta que no han sido encontrados en la Península Ibérica los modelos metálicos similares a los existentes en la cultura Vilanoviana". Já Bettencourt \& Rodrigues (2013) referem, para as paletas do afloramento gravado do Fieiral, a possibilidade de uma cronologia entre a Idade do Ferro e a Romanização.

Tendo em conta estes dados, e estando, ainda, por estabelecer um balizamento cronológico seguro para estas figurações, propomos, sob reserva, que as paletas de Cabanas na bacia do Ave (Fig. 11A) se possam incluir num período cronológico compreendido entre a Idade do Bronze e a Idade do Ferro, correspondendo assim a um momento a adições realizadas em antigos lugares com arte de tradição esquemática.
Incluímos igualmente num novo "ciclo artístico" a gravação de podomorfos em afloramentos com arte de tradição esquemática, presentes apenas no Penedo da Pegadinha, em Vieira do Minho (Fig. 12A). Cremos que, tal como as paletas, terão sido gravados numa época distinta relativamente aos outros motivos, no âmbito de uma revisitação e de alteração dos sentidos dos signos anteriormente gravados. Estes motivos encontram-se representados tanto na Arte Atlântica como na arte de tradição esquemática ocorrendo, na maioria das vezes, de forma isolada (BETTENCOURT in press).

Relativamente a paralelos para as representações podomórficas do Penedo da Pegadinha podemos mencionar um dos afloramentos gravados de Tripe, em Chaves (Fig. 12B). Baptista (1983-84) coloca este lugar no seu grupo II atribuindo-lhe uma cronologia que vai desde o Bronze Final à Alta Idade Média. Na bacia do Ave a manifesta falta de dados, torna difícil estabelecer uma atribuição cronológica para estas figurações pelo que, com todas as reservas, colocamos os motivos podomórficos do Penedo da Pegadinha (Fig. 12A) no $1^{\circ}$ milénio a.C., num período em que se afiguravam novas lógicas protagonizadas por mudanças ideológicas, políticas e socioeconómicas (CARDOSO 2015).

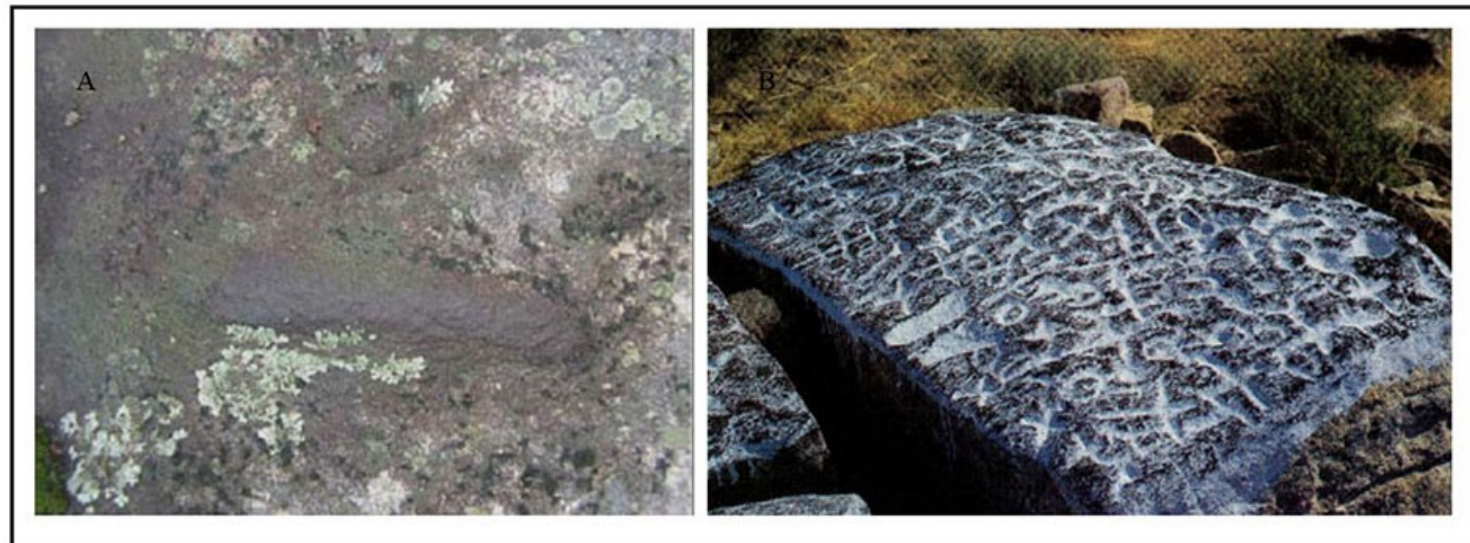

Fig. 12. A - Vista de pormenor do podomorfo da Pegadinha, Vieira do Minho ( http://patrimonio.cm-vminho.pt/); B - Vista geral de um dos afloramento gravados de Tripe, Chaves (BAPTISTA 1993: 50).

Fig. 12. A - Detailed view of the footprint of Pegadinha, Vieira do Minho (http://patrimonio.cm-vminho.pt/); B - General view of one of the carved outcrop from Tripe, Chaves (BAPTISTA 1993: 50).

Já numa quarta fase de gravação regional ou terceiro ciclo artístico surgem na bacia do Ave as representações de cruciformes e de um pentagrama. Os primeiros motivos são abundantemente representados, tal como acontece na maioria dos sítios com arte de tradição esquemática. Existem variadas tipologias para estas representações sendo os cruciformes da área geográfica em estudo, estilisticamente semelhantes a muitos outros encontrados no Noroeste português. Encontram-se pois paralelos estilísticos para a maioria destes motivos em sítios rupestres como Lamelas, em Ribeira de Pena (MARTINS 1981); Tripe (rocha 1), em Chaves
(BAPTISTA 1983-84); em vários afloramentos no Monte de Góis, nomeadamente na Mata das Cruzes e no vale do rio Ouro, em Caminha (VALDEZ 2010) e na rocha 15 do Gião 1, Arcos de Valdevez, um dos sítios mais exemplificativos da diversificada iconografia dos cruciformes (FONTES 1932). Existe polémica relativamente à interpretação destes signos pelo que só usámos esta expressão em presença de cruzes latinas (com ou sem bases retangulares ou circulares) (Fig. 13) e gregas, entre outras declaradamente não antropomórficas.

Em relação à sua atribuição cronológica há investigadores que as colocavam em épocas histó- 
ricas como Lorenzo Ruza (1946). Porém Baptista (1983-84) inseriu os cruciformes no seu grupo II, atribuindo-lhes uma cronologia desde o Bronze Final à Alta Idade Média. Este autor considera a possibilidade de alguns deles serem representações de antropomorfos. Na bacia do Ave o que considerámos cruciformes poderão ser formas de cristianização de antigos locais significantes; símbolos apotropaicos ou cruzes de termo de cronologia histórica.

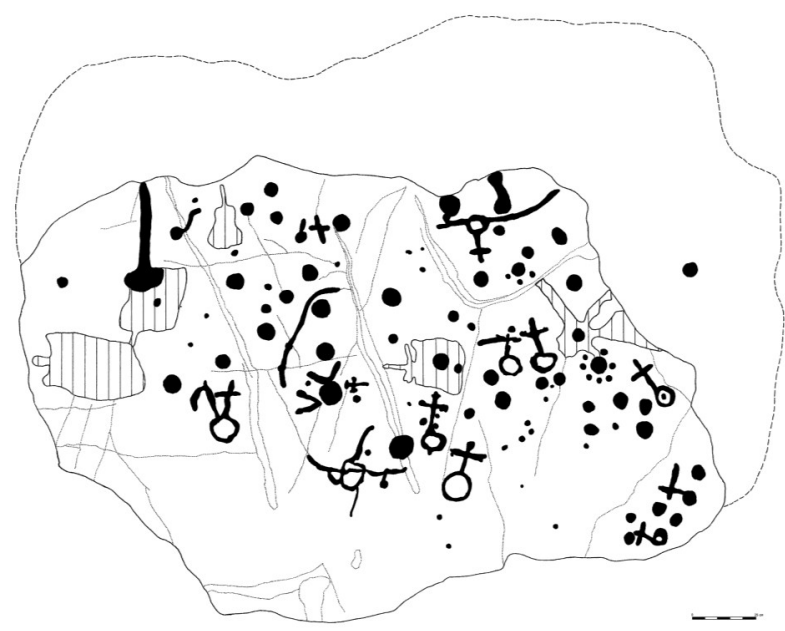

Fig. 13. Cruciformes de Cabanas, Fafe (SAMPAIO \& Garcia Diez 2000).

Fig. 13. Cruciforms from Cabanas (Huts), in Fafe (SAMPAIO \& GARCIA DieZ 2000).

Por último, e nesta mesma última fase de reutilização da Arte de tradição esquemática, colocamos o pentagrama ou pentalfa. Este é, também, um motivo raramente representado na arte rupestre em geral, pelo que, na bacia do Ave, ocorre apenas duas vezes na Laje dos Cantinhos/Zebral. Segundo Coimbra (2005) estes motivos têm uma longa sobrevivência temporal que se estende desde meados do $4^{\circ}$ milénio a.C. até à atualidade, podendo ser pintados ou gravados e executados por meio de diferentes técnicas como, por exemplo, através de incisão profunda ou filiforme. No Norte de Portugal não temos argumentos para considerar que recuem até datas tão antigas. Nesta área podem enumerar-se vários exemplos gravados, sendo de referir a sua existência na rocha 2 da Ribeira de Piscos, em Vila
Nova de Foz Côa; no Vale da Casa, também em Vila Nova de Foz Côa; em Lamelas, Ribeira de Pena (MARTINS 1981); em Montedor, Viana do Castelo (CARDOSO 2015); na rocha 1 de Molelinhos, Tondela; na Laje da Fechadura, Sertã e na Aldeia Velha, em Góis (COIMBRA 2004, 2005, 2009; LiMA 2008-2009). Existe, ainda, um pentagrama isolado, num afloramento contíguo ao forte da Praia dos Ingleses, em Afife, Viana do Castelo ${ }^{2}$.

Paralelos estilísticos para os pentagramas da Laje dos Cantinhos (Fig. 14A) são os de Lamelas, Ribeira de Pena (Fig. 14B) que se encontram, também, num afloramento com motivos de tradição esquemática. Tanto num caso como no outro, terão sido adicionados num momento mais tardio, possivelmente já na Idade Média ou Moderna, no âmbito de revisitações a estes locais.
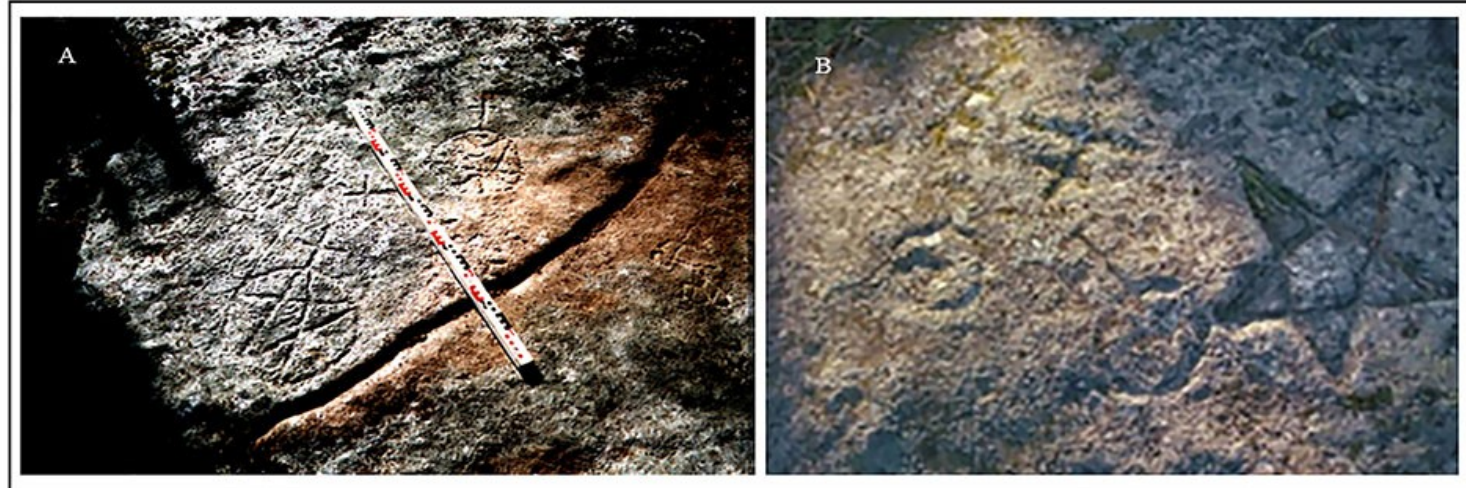

Fig. 14. A - Pentagrama da Laje dos Cantinhos (Fonte: http://www.geira.pt); B - Pentagrama de Lamelas, Ribeira de Pena (http:// terrasdepena.blogspot).

Fig. 14. A - Laje dos Cantinhos pentagram (http://www.geira.pt); B - Lamelas pentagram, Ribeira de Pena (http://terrasdepena.blogspot).

${ }^{2}$ Informação pessoal de Ana M. S. Bettencourt. 


\section{CONSIDERAÇÕES FINAIS}

Apesar de preliminar este trabalho pretendeu contribuir para aumentar os conhecimentos sobre a arte rupestre pós-paleolítica de ar livre do Noroeste da Ibéria, a partir do estudo de uma bacia fluvial, a do rio Ave.

Sintetizando, verifica-se que a arte de tradição esquemática da bacia do Ave se agrupa numa zona mais interior e montanhosa e próxima de linhas de água; que os afloramentos se implantam maioritariamente em vertentes recortadas e declivosas; que os afloramentos gravados se dispõe maioritariamente na horizontal ou com ligeira inclinação, com exceção da Pedra Escrita; que o reportório iconográfico é constituído, predominantemente, por quadrados ou retângulos segmentados e covinhas e, excecionalmente, por círculos simples ou com covinha interior e por antropomorfos esquemáticos (com penachos e ou toucados e com mãos grandes). Estes últimos parecem ocupar posições periféricas em relação aos quadrados/ retângulos segmentados o que parece indiciar serem de cronologia posterior. Este tipo de manifestação simbólica e atuante na paisagem das populações préhistóricas terá tido origem no Neolítico Médio/Final (finais do $5 \%$ inícios do $4^{\circ}$ milénios a.C., persistindo pelo Calcolítico ou Inícios da Idade do Bronze (pelos $3^{\circ}$ e $2^{\circ}$ milénios a.C.). A partir do $1^{\circ}$ milénio a.C. este tipo de gramática decorativa parece perder os seus sentidos originais e novos signos, como os podomorfos e as paletas, vão introduzindo ou adicionando novos sentidos aos antigos lugares gravados. Mais tarde, cruzes e pentagramas, materializam novamente a frequência destes lugares e as suas longas biografias.

Em termos da cosmogonia das populações que gravaram a arte de tradição esquemática parece ter sido importante uma visão animista do mundo, onde elementos como os afloramentos, os lugares de passagem, de nascentes e de cursos de água seriam importantes.

\section{AGRADECIMENTOS}

As autoras agradecem aos revisores todas as sugestões que permitiram melhorar o texto.

\section{BIBLIOGRAFIA}

ABreu, M. 2012. Rock-Art in Portugal: History, Methodology and Traditions. Tese de Doutoramento, Universidade de Trás-os-Montes e Alto Douro.

AlmeidA, C. \& Mourinho, A. 1981. Pinturas Esquemáticas de Penas Róias. Terra de Miranda do Douro. Arqueologia, 3: 43-48.

ALVES, L. 2001. Rock art and enchanted moors: the significance of rock carvings in the folklore of North-west Iberia. In: R. J. WALLIS \& K. LEIMER (Eds.), A Permeability of Boundaries? New Approaches to Archaeology of Art, Religion and Folklore, Bar International Series, 936, Oxford, Archaeopress: 71-78.

Alves, L. 2003. The movement of signs - Pos-glacial rock art in North-western Iberia. PhD. Thesis, University of Reading.
ALVES, L. 2008. O Sentido dos Signos - reflexões e perspectivas para o estudo da Arte Rupestre Pós-Glaciar no Norte de Portugal. In: RODRIGO BALBÍN BeHRMANN (Ed.). Arte Prehistórico al aire libre en el Sur de Europa, Castilla y León, Consejeria de Cultura da Junta de Castilla y León: 381-490.

Alves, L. 2011. Génio e Talento do Passado. A arte gravada do Penedo do Encanto e da Chã da Rapada, ADERE-PG Associação de Desenvolvimento das Regiões do Parque Nacional da Peneda Gerês/ Arqueohoje, Lda.

Alves, L. 2013. Monte de Góis, Caminha. Um santuário rupestre nas margens do rio Minho. In: ANA M. S. Bettencourt (Ed.) The Prehistory of the NorthWestern Portugal, Territórios da Pré-História em Portugal, Vol. 2, Braga /Tomar, CEIPHAR/ CITCEM.

Alves, L.; Bradley, R. \& FÁBregas Valcarce, R. 2013. Tunnel Visions: a decorated Cave at El Pedroso, Castile, in the light of fieldwork. Proceedings of the Prehistoric Society, 79:193-224.

ANATI, E. 1968. El arte rupestre galaico-portugues. Simpósio Internacional de Arte Rupestre, Barcelona. Instituto de Prehistoria y Arqueologia: 195-254.

BAPTISTA, A. 1980. Introdução ao estudo da arte préhistórica do noroeste peninsular. As gravuras rupestres do Gião. Minia, 3 (4), $2^{\text {a }}$ Série: 80-100.

Batista, A. 1981. A arte do Gião. Arqueologia 3: 56-66.

BAPTISTA, A. 1983/84. Arte Rupestre do Norte de Portugal: uma perspectiva. Actas do Colóquio InterUniversitário do Noroeste, Porto, Novembro de 1983. Portugália, 4-5, nova série: 71-82.

BAPtistA, A. 1986. Adenda à notícia explicativa da Carta Geológica de Portugal, folha 1-D (Arcos de Valdevez) - Arqueologia. Terra de Val de Vez, 9: 97-116.

BAPTista, A. 1993. Arte rupestre pós-glaciária. Esquematismo e abstracção. In: J. AlARCÃo, (Coord.), História da Arte em Portugal: Do Paleolitico à Arte Visigótica. Vol.1, Lisboa, Alfa: 31-55.

Baptista, A. 1997. Arte megalítica no planalto de Castro Laboreiro (Melgaço, Portugal e Ourense, Galiza). Actas do III Coloquio Internacional de Arte Megalítico. Brigantium 10:191-216.

Bello Dieguez, J. 1994. Grabados, pinturas y idolos em Dombate (Cabana, La Coruña). Grupo de Viseu o grupo noroccidental? Aspectos taxonómicos y cronológicos. O Megalitismo no Centro de Portugal. CEPBA, 2: 287-304.

Bosh GiMPERA, P. 1923. L'estat actual del coneiximent de la civilització Neolítica i Eneolítica de la Península Ibèrica. Anuari del Institut d'Estudis Catalans, 6: 516-527.

BETTENCOURT, A.M.S. 2009. Entre os montes e as águas: ensaio sobre a percepção dos limites na pré-história da faixa costeira entre o Minho e o Lima (NW português). In: A.M.S. BetTencourt \& L.B. AlveS (Eds.), Dos Montes, das Pedras e das Águas. Formas de Interacção com o Espaço Natural da Pré-história à Actualidade, Braga: CITCEM/APEQ:131-162.

BetTencourt, A.M.S. 2013a. Tumulus of Leira das Mamas, Lamas, Braga. In: A.M.S. BETTENCOURT (Eds.) The Prehistory of the North-Western Portugal, Territórios da Pré-História em Portugal, Vol. 2, Braga /Tomar, CEIPHAR/CITCEM: 149-154. 
BetTenCOURT, A.M.S. 2013b. The rock engravings of Chã da Rapada, Britelo, Ponte da Barca / As gravuras rupestres do Chã da Rapada, Britelo, Ponte da Barca. In: A.M.S. BetTEnCOURT (Eds.) The Prehistory of the NorthWestern Portugal / A Pré-História do Noroeste Português, Territórios da Pré-História em Portugal, vol. 2, Braga/Tomar: CEIPHAR/CITCEM: 162-168.

Bettencourt, A.M.S. 2014a. Laje dos Cantinhos. In: A.M.S BetTencourt. \& E. ABAD-VIDAL (Eds.) CVARN-Corpus Virtual de Arte Rupestre do Noroeste Português (www.CVARN.org).

Bettencourt, A.M.S. 2014b. Penedo da Pegadinha. In A.M.S. BetTEnCOURT, \& E. ABAD-VidA, (Eds.), CVARN-Corpus Virtual de Arte Rupestre do Noroeste Português (www.CVARN.org.)

Bettencourt, A.M.S.; SAnches, M.; Dinis, A. \& Cruz, C. 2004. The rock engravings of Penedo do Matrimónio in Campo de Caparinho. Journal of Iberian Archaeology, 6: 61-82.

Bettencourt, A.M.S. \& Rodrigues, A. 2013. As gravuras rupestres do Fieiral, Castro Laboreiro, Melgaço. In: A.M.S BetTenCOURT (Ed.) The Prehistory of the North-Western Portugal, Territórios da PréHistória em Portugal, Vol. 2, Braga/Tomar, CEIPHAR/CITCEM: 132-138.

Bettencourt, A.M.S.; ABAD-Vidal, E. \& Rodrigues, A. in press. CVARN-Rock art virtual corpus of Northwestern Portugal. A multimedia tool to investigate and disclose the pos-palaeolithic rock art. In: A.M.S. BETTENCOURT; M. SANTOS EstÉvEZ; D. CARDOSO, \& H.A. SAMPAIO (Eds.), Recorded Places, Experienced Places. The Holocene Rock Art of the Iberian Atlantic Façade, Bar International Series, Oxford, Archaeopress.

Bradley, R. 1997. Rock Art and the Prehistory of Atlantic Europe. Signing the Land. London/NewYork, Routledge.

BradLEy, R. 2002. Access, Style and Imagery: The Audience for Prehistoric Rock Art in Atlantic Spain and Portugal, 4000-2000 BC. Journal of Archaeology, 21 (3): 231-247.

Bradley, R. 2009. Image and Audience - Rethinking Prehistoric Art. Oxford, University Press.

Bradley, R.; Fábregas Valcarce, R.; Alves, L. \& VILAseco VÁzQuez, X. 2005. El Pedroso a prehistoric cave sanctuary in Castille. Journal of Iberian Archaeology, 7: 125-156.

BREUIL, H. 1917. La roche peinte de Valdejunco, à la Esperança, prés Arronches. Terra Portuguesa, 3 (13-14): 17-27.

Cardoso, D. 2015. A Arte Atlântica do Monte de S. Romão (Guimarães) no Contexto da Arte Rupestre Póspaleolítica da Bacia do Ave - Noroeste Português. Tese de Doutoramento, Universidade de Vila Real e Trás-os-Montes.

Carrera Ramirez, F. 2011. El Arte Parietal en Monumentos Megalíticos del Noroeste Ibérico: Valoración, Diagnóstico, Conservación. BAR, International Series 2190. Oxford, Archaeopress.

CoImBrA, F. 2004. A Arte Rupestre do concelho de Barcelos (Portugal). Anuário Brigantino, 27: 37-70.

CoImBrA, F. 2005. Arte Rupestre e lendas populares. Revista de Portugal 2, nova série: 10-14.
COIMBRA, F. 2009. Portuguese Rock Art in a Protohistoric context. Arkeos, Perspectivas em Dialogo, 24: 111-130.

Costa, F. 2007. A Gestão das Águas Públicas - O Caso da Bacia Hidrográfica do Rio Ave no Periodo 19021973. Tese de Doutoramento, Universidade do Minho.

Gonçalves, A. \& CruZ, D. 1994. Resultado dos trabalhos de escavação da Mamoal de Madorras (S. Lourenço de Ribapinhão, Sabrosa, Vila Real). Estudos Pré -históricos, 2:171-232.

DíAZ-GuARDAmino, M. 2010. Las Estelas Decoradas en la Prehistoria de la Península Ibérica. Tese de Doutoramento, Universidad Complutense de Madrid.

Figueiredo, S. 2013. A Arte Esquemática do Nordeste Transmontano: Contextos e Linguagens. Tese de Doutoramento, Universidade do Minho.

FONTES, J. 1932. Sobre algumas figuras rupestres do santuário pré-histórico do Gião. Revista de Arqueologia, 1: $75-82$.

Fontes, L. \& RoRIZ, A. 2007. Património Arqueológico e Arquitectónico de Vieira do Minho. Vieira do Minho, Município de Vieira do Minho.

FONTES, L. \& RORIZ, A. 2012. Inventário de sitios e achados arqueológicos do concelho de Vieira do Minho. Vieira do Minho, Trabalhos Arqueológicos da U.A.U.M./Memórias 22.

Gell, A. 1998. Art and Agency: An Anthropological Theory. Oxford, Clarendon Press.

Gomes, M. 2010. Arte rupestre do Vale do Tejo um Ciclo Artístico-Cultural Pré e Proto- Histórico. Tese de Doutoramento, Universidade Nova de Lisboa.

Gomes, L.; Carvalho, P.; Perpétuo, J.; Marrafa, C. 1998. O Dólmen de Areita (S. João da Pesqueira, Viseu). Estudos Pré-históricos, 6: 33-93.

Ingold, T. 2000. The Perception of the Environment. Essays on Livelihood, Dwelling and Skill. London and NewYork, Routledge.

LIMA, A. 2008-2009. O Outeiro Rupestre da BotelhinhaPegarinhos (Alijó): Registo e análise do conjunto de rochas gravadas. Portugália, 29-30, nova série: 85-138.

Lorenzo-RuZA, R. 1946. Acerca de los signos del petroglifo de Eira d'os Mouros. El Museo de Pontevedra, 4: 137-142.

Martins, A. 2006. Gravuras rupestres do Noroeste Peninsular da Chã da Rapada. Revista Portuguesa de Arqueologia, 9 (1): 47-70.

MARTINS, M. 1981. O santuário rupestre de Lamelas (Ribeira de Pena). Ribeira de Pena, Câmara Municipal de Ribeira de Pena.

OBERMAIER, H. 1925. Die Bronzezeitlichen Felsgravieringen von Norwestspanien (Galicien). Jahrbuch fur Prahistoriche und Ethnographische Kunst, 1: 51-59.

Ribeiro, N. 2008. Open air Rock Art in the Ceira and Alva River Valleys-Some Symbols. In: FERNANDO CoImbra \& Dubal Leo (Eds.), Proceedings of the XVth World Congress-Session WS34 - (Lisbon, 4-9 September 2006), vol. 25: 43-49, BAR International Series 1973, Oxford: Archeopress.

SAmpaio, J. \& Garcia Diez, M. 2000. A arte rupestre do Planalto da Lameira, Celorico de Basto e Fafe. Revista de Guimarães, 110: 189-207. 
SANCHES, M.J. 1990. Os abrigos com pintura esquemática da Serra de Passos - Mirandela, no conjunto da arte rupestre desta região. Algumas reflexões. Revista da Faculdade de Letras - História, 8, 2a série: 336354.

SANCHES, M.J. 1997. Pré-história Recente de Trás-osMontes e Alto Douro (O Abrigo do Buraco da Pala no Contexto Regional). Porto, Sociedade Portuguesa de Antropologia e Etnologia 2.

SANCHES, M.J. 2002. Spaces for social representation, choreographic spaces and paths, in the Serra de Passos and surrounding lowlands (Trás-os-Montes, Northern Portugal) in Late Prehistory. ARKEOS, 12: 65 -105 .

SANCHES, M.J. 2003. Escrever na paisagem sentido para as "artes rupestres". In: V. O. JoRGE (Coord), Arquitectando Espaços da Natureza à Metapolis. Actas da $7^{\mathrm{a}}$ Mesa-Redonda da Primavera, Porto-Coimbra, DCTP/FLUP: 85-104.

SANCHES, M.J. 2006. Abrigos com pintura rupestre esquemática da Serra de Passos/St ${ }^{\mathrm{a}}$ Comba. In: C.A.B AlmeIDA (Coord.), História do Douro e do Vinho do Porto: História Antiga da Região Duriense, Vol. 1, Porto, Afrontamento: 126-129.

SANCHES, M.J. 2008-2009. Arte dos Dólmens do noroeste da península Ibérica: uma revisão analítica. Portugália, nova série, vol. XXIX-XXX: 5-42.

SANTOS, A. 2008. Uma abordagem hermeneutica fenomenológica à arte rupestre da Beira Alta: o caso do Fial (Tondela, Viseu). Estudos Pré-históricos, vol. 13, CEPBA.

SAntos Estévez, M. 2005. Sobre la cronología del arte rupestre atlántico en Galicia. Arqueoweb7(2). (http://www.ucm.es/info/arqueoweb/numero7_2/ conjunto7_2.htm).
SANTOS JÚNIOR, J. 1934. As pinturas pré-históricas do Cachão da Rapa. Trabalhos da Sociedade Portuguesa de Antropologia e Etnologia, 6: 185-222.

SANTOS JÚNIOR, J. 1978. As gravuras rupestres do Outeiro Machado (Vale d'Anta-Chaves). Trabalhos de Antropologia e Etnologia, 23 (2-3): 207-234.

Sarmento, F. 1999. Antiqua - Apontamentos de Arqueologia. Guimarães, Sociedade Martins Sarmento.

SheE Twohig, E. 1981. A pedra decorada de Ardegães de Águas Santas (concelho da Maia). Arqueologia, 3 : 49-55.

Silva, E. 1988. A Mamoa de Afife: breve síntese de 3 cam panhas de escavação. Trabalhos de Antropologia e Etnologia, 28 (1-2): 127-132.

SilvA, E. 1997. A arte megalítica da costa Norte de Portugal. Brigantium, 10: 179-189.

SiLVA, F. 1984. A arte parietal do dólmen da Aliviada Escariz. Aveiro e o seu Distrito, 33: 37-45.

SILVA, F. 2004. Megalitismo e tradição megalítica no concelho de Arouca: três mil anos de arquitectura funerária. In: A.M.S.P. SILVA (Coord.), Memórias da Terra. Património Arqueológico do Concelho de Arouca, Arouca, Câmara Municipal: 45-203.

TeIXeIRA, L. 2012. Abrigos com Pinturas Rupestres de Trás -os-Montes e Alto Douro (Pala Pinta, Penas Róias e Cachão da Rapa). Paisagens, Signos e Cultura Material. Dissertação de Mestrado, Universidade Nova de Lisboa.

VALdeZ, J. 2010. A Gravura na Arte Esquemática do Noroeste Peninsular - O Caso do Monte de Góios (Lanhelas, Caminha). Dissertação de Mestrado, Universidade do Porto. 